This is a self-archived version of an original article. This version may differ from the original in pagination and typographic details.

Author(s): Ahtiainen, Juha

Title: Physiological and Molecular Adaptations to Strength Training

Year: 2019

Version: Accepted version (Final draft)

Copyright: (C) Springer International Publishing AG, part of Springer Nature 2019.

Rights: In Copyright

Rights url: http://rightsstatements.org/page//nC/1.0/?language=en

Please cite the original version:

Ahtiainen, J. (2019). Physiological and Molecular Adaptations to Strength Training. In M.

Schumann, \& B. R. Rønnestad (Eds.), Concurrent Aerobic and Strength Training : Scientific Basics and Practical Applications (pp. 51-73). Springer. https://doi.org/10.1007/978-3-319-75547-2_5 


\title{
Chapter 5. Physiological and molecular adaptations to strength training
}

\begin{abstract}
High muscle contraction forces that lead to gains in muscle function, size, and strength characterize resistance exercise training. The purpose of this chapter is outline the adaptations in myofiber size and metabolism that occur by stimuli of hormones and local growth factors, mechanical and metabolic stress of muscle tissue, and myofibrillar disruptions induced by a resistance exercise bout. The chapter will highlight the network of intracellular pathways (including mTOR signaling) that ultimately lead to increases in gene expression and protein synthesis. Accumulation of acute exercise responses by systematic training over time modulate muscle proteome that can be observed as changes in skeletal muscle phenotype.
\end{abstract}

Key words: Resistance exercise, muscle growth, neuromuscular performance, signaling pathways

\section{(Bodytext)}

Resistance exercise training (RT) can be functionally defined as the progressive overload of a skeletal muscle that is characterized by high muscle contraction force and anaerobic ATP resynthesis. Longterm RT elicits a range of physiological adaptations that contribute to changes in muscle function. Specifically, RT stimulates adaptive machinery responsible for increased maximal contractile force output that is primarily promoted by the combined effect of enhanced muscle activation and muscle fiber hypertrophy ${ }^{1}$. Skeletal muscles play an essential role in locomotion and in the control of whole body metabolism and, hence, RT is widely employed by athletes to improve sport-specific performance, by general population to promote health, lean body mass and general fitness, and in rehabilitation to prevent loss of muscle mass and strength in pathological states ${ }^{2,3}$.

Skeletal muscle can exhibit remarkable plasticity in response to RT. Adjustments within the muscle milieu to mechanical and metabolic demands of RT act to attenuate cellular stress during subsequent exercise sessions ${ }^{4}$. The major morphological adaptation that is specific to RT is a marked increase in muscle cross-sectional area (CSA) of exercised muscles. However, the design of the RT program (i.e. volume, intensity, and frequency of RT sessions, mode of muscle actions used, progression, periodization, variety of RT stimulus, and integration of RT to other fitness training) specifically influences the subsequent chronic physiological adaptations ${ }^{5}$. Also factors such as heredity, sex, biological age, exercise training history, health status and possible medication, diet and nutritional supplements, personal lifestyle and habitual physical activity/inactivity, other physical and psychological stressors (e.g. work-related) and coping with mental stress, training adherence as well as environmental factors can influence chronic outcomes of RT ${ }^{4,6}$.

\section{Changes in muscle size}

Increases in skeletal muscle size (i.e. hypertrophy) are the most striking adaptations that occur in response to RT. M uscle hypertrophy is detectable after few weeks from the beginning of the regular RT and proceeds in a linear manner at least for the first few months of training ${ }^{1}$. Typically, on average 6-9 \% increases in muscle size are observed in quadriceps muscles following few months of RT in previously untrained individuals. ${ }^{7}$ Reaching the individual maximum in muscle mass gains, however, may require several years of systematic RT.

In research, greater hypertrophy is typically observed in upper body muscles compared to lower extremity muscles, possible due to higher locomotive activity in leg muscles that may reduce the 
potential for further muscular responses induced by the exercise stimulus ${ }^{1}$. Age and sex may not have substantial effects on the initial RT-induced muscle hypertrophy ${ }^{1,8,9}$. However, in women and in older individuals muscle hypertrophy may remain only modest over the years of systematic RT when their responses are compared to those observed in younger adult men. RT-induced muscle hypertrophy occurs specifically in trained muscles and is depending on the design of the RT program. In an untrained state, various kinds of training regimens can induce muscle hypertrophy during the first months of training ${ }^{10}$. For maximizing muscle growth by long-term RT, however, the RT program should principally include multiple sets per exercise with 6-12 heavy repetitions per set and relatively short rest intervals between the sets. Furthermore, several different kinds of exercises should be employed per muscle group in the context of split training routine ${ }^{5,11,12}$.

\section{Changes in myofiber size and fiber type transitions}

Skeletal muscle hypertrophy induced by RT occurs through an increased protein content of individual muscle fibres. Most of the skeletal muscle fibre cytoplasm is occupied by myofibrils with the most abundant proteins being myosin and actin filaments. Thus, RT-induced fibre hypertrophy is primarily a result of the biosynthesis and accumulation of new contractile myofilaments, with concomitant expansion of fibre volume ${ }^{13-15}$. The possible mechanism of fiber growth is an increased CSA and proliferation of myofibrils that results in increased contractile material arranged in parallel and, consequently, an increase in force production capacity. These increases appear especially in fast-twitch type II fibres following RT ${ }^{1}$.

Skeletal myofibers develop distinct phenotypic characteristics during the postnatal period, and therefore the distribution of fiber types is genetically determined. M uscle fibers are characterized as type 1 (slow-twitch) and 2A and 2X (fast-twitch) according to the predomination of their myosin heavy chain ( $\mathrm{MHC}$ ) polymorphisms. Although the fiber-type profile is genetically established, fibers may be remodeled throughout the lifespan by diverse physiological stimuli such as the training status ${ }^{16}$. M any human studies have demonstrated that prolonged RT promotes the conversion of muscle fibers from the glycolytic type $2 X$ fibers to the more oxidative type $2 \mathrm{~A}$ fibers, whereas the proportion of type I fibres remains rather unchanged ${ }^{17}$. During fiber-type transformation, the expression of $\mathrm{MHC}$ isoforms and mitochondrial density, oxidative phosphorylation (OXPHOS) activity, vasculature, and fatigue resistance are switched accordingly. The ability to "shift" skeletal muscle fibers from a more glycolytic fiber to a more oxidative fiber is critical for energy availability to support skeletal muscle contractile activity during the exercise ${ }^{18}$.

\section{Changes in muscle architecture}

Muscle architecture is defined as the structural arrangement of muscle fibers and connective tissue elements within the muscle relative to the line of force generation at the macroscopic level. M uscle architecture is an important determinant of muscle's mechanical function by affecting the forcevelocity relationship. ${ }^{19} \mathrm{Key}$ components of this relationship are fiber length and pennation angle. Muscle fascicles are bundles of muscle fibers and the angle in which they attach to tendon or aponeurosis (i.e. pennation angle) can be investigated by ultrasound techniques in vivo.

Physiological CSA (i.e. the area of the cross section of a muscle perpendicular to its fibers) is closely related to the force produced by the muscle and is largely determined by the pennation angle. On the other hand, muscle velocity is proportional to muscle fiber length ${ }^{20}$.

Several studies have shown that RT-induced structural remodeling of the contractile machinery can increase pennation angles to a certain extent in the hypertrophied muscles ${ }^{21}$. These architectural changes in trained muscles affect the manner how force is transmitted from contracting muscle 
fibers to tendons and bones. RT-induced increases in pennation angles allows greater contractile material deposition (i.e. addition of sarcomeres in parallel) that further increases physiological CSA and, consequently, enabling an increase in the force generating capacity of the muscle.

$M$ athematically, extensive increases in pennation angle can negatively affect force production of the contracting muscle due to unfavorable arrangement of muscle fibers relative to the axis of force generation to tendon. Thus, when pennation angle increases by excessive hypertrophy, force produced per physiological CSA may decrease ${ }^{22}$. On the other hand, increases in myofibrillar size without changes in muscle architecture (i.e. increase in myofibrillar packing density or lateral force transmission) may explain changes in specific tension (i.e. force exerted by the fibers per unit of physiological CSA). That may partly explain why initial strength gains by RT can be achieved without measurable increase in muscle CSA ${ }^{22,23}$.

\section{Satellite cells and myonuclei addition}

Skeletal muscle satellite cells are quiescent myogenic precursor cells, located adjacent to muscle beneath the basal lamina but outside the sarcolemma. The role of satellite cells in muscle regeneration is well established. Satellite cells can be activated in response to traumatic lesions requiring muscle regeneration. Once activated, satellite cells proliferate and/or fuse together with preexisting fibers to regenerate muscle tissue ${ }^{24}$.

Also, increased muscle activity during exercise can induce activation and proliferation of satellite cells. Subsequent fusion with an existing myofiber results in the addition of a myonucleus to the fiber syncytium, thereby increasing the total number of myonuclei. The number of myonuclei is a critical determinant of protein synthesis capacity by providing the amount of DNA necessary to sustain gene transcription ${ }^{25}$. The proposed role of the satellite cells in muscle hypertrophy revolves around the concept of a myonuclear domain, meaning that a single myonucleus supports a certain volume of cytoplasm ${ }^{24,26}$. M yofibers are composed of many myonuclear domains and the myonuclear domain size is considered as virtually constant. Satellite cells provide a source for new myonuclei at a rate sufficient to maintain an almost constant myonuclei to-cytoplasmic ratio during skeletal muscle hypertrophy in response to chronic RT. Indeed, several studies have demonstrated that muscle fiber hypertrophy is accompanied by a concomitant increase in satellite cell and/or myonuclear content during chronic RT in humans ${ }^{25}$.

It appears, however, that at least modest muscle hypertrophy can be achieved without the addition of new myonuclei. Thus, the existing myonuclei may have the intrinsic ability to increase their RNA and protein synthesis capacity to such an extent that additional myonuclei are not required to support initial muscle fiber growth ${ }^{2,27}$. However, there may exist a ceiling size of the myonuclear domain area beyond which a fiber will not be able to continue hypertrophy extensively unless more myonuclei are incorporated into the growing fiber ${ }^{24}$. Furthermore, it has been suggested that satellite cells occasionally need to fuse to the muscle fibers to maintain adult muscle mass. It is currently not well known whether other circulating stem cell populations with myogenic potential, together with satellite cells, are activated during the RT-induced hypertrophic response ${ }^{25}$.

Activation of satellite cells and their myonuclear addition has been proposed to play a pivotal role in the phenomenon of "muscle memory" in RT that may be very long lasting in humans. According to the suggested theory, previously untrained fibers recruit myonuclei from activated satellite cells to support hypertrophic growth. During the subsequent detraining and muscle atrophy, myonuclei are protected against the elevated apoptotic activity and the higher number of myonuclei is retained. When muscles are subjected to hypertrophic re-training, muscles grow faster compared to initial RT period. However, convincing evidence of this theory is still lacking in humans ${ }^{28}$. 


\section{Connective tissue adaptations to resistance training}

Collagen rich connective tissue constructs tendons and ligaments. In addition, connective tissue exists around and within skeletal muscle. Tendons play a main role in transmitting contractile force to bone and producing elastic energy, while ligaments stabilize joints preventing excessive movements that could damage the joint. Intramuscular connective tissue contributes to passive stiffness in the musculature and force transmission between muscle fibers. Adaptations in the connective tissues occurs specifically only in structures that are exposed to loading 29,30 .

As skeletal muscles become stronger by RT, intramuscular connective tissues as well as tendons and ligaments also adapt to support increased muscular strength by increasing CSA ${ }^{31,32}$. The turnover and, thus, renewal of tissue is somewhat slower in connective tissue in the musculoskeletal system compared to that of contractile proteins in the skeletal muscle cells itself. Therefore, tendons appear to hypertrophy at a somewhat slower rate compared to muscles by RT ${ }^{33,34}$. However, increases in tendon stiffness can occur before tendon hypertrophy. That is possibly due to adaptations in internal structures of the tendon, e.g. modulation of cross-link composition between collagen molecules that improve mechanical properties of the tendon ${ }^{35}{ }^{36}$. Increased tendon stiffness may enhance the utilization of elastic energy during stretch shortening cycles and increase the rate of force development during the explosive (fast) muscle actions ${ }^{33,37}$.

Bone mass, density and architecture are modified to sustain strains produced by the mechanical load. Osteocytes are involved in the turnover of bony matrix through various mechanosensory mechanisms. Bone adapts to external stress specifically at the loaded sites when the magnitude of peak strain is adequate. The most effective intervention for improving bone mineral density (BMD) appears to be exercise characterized by relatively large loading magnitudes and rates. Long-term RT of sufficient intensity and volume has been shown to increase BMD ${ }^{38-41}$.

\section{Metabolic adaptations to resistance training}

Heavy resistance exercise (i.e. several sets with submaximal loads and short rest periods between the sets) can induce acute decrease in ATP, phosphocreatine (PCr) and glycogen storages and marked increase in the concentration of blood lactate, indicating a high rate of anaerobic glycolysis. Consequently, depleted glycogen storages may partly induce post-exercise muscle fatigue ${ }^{42-44}$.

Depending of the exercise-induced myofibrillar disruptions and volume of the loading protocol used and the content of carbohydrates in diet, glycogen storages may be replenished within a couple of days following exercise ${ }^{45-48}$. As a result of chronic RT, the activity of anaerobic enzymes (e.g. creatine phosphokinase, myokinase, and phosphofructokinase) has been shown to increase. Furthermore, intramuscular PCr and glycogen concentrations increase ${ }^{49,50}$. Chronic RT may also increase skeletal muscle oxidative capacity ${ }^{51,52}$. These adaptations may lead to improvements in energy metabolism and especially in glycolytic capacity in trained muscle by long-term RT ${ }^{2}$.

Skeletal muscle is the main tissue for glucose disposal accounting for up to $80 \%$ of insulin mediated glucose uptake in the postprandial state. During the resistance exercise bout, glucose uptake increases significantly in loaded muscles ${ }^{51,53}$. Research evidence suggests that chronic RT is effective in improving insulin sensitivity when the intensity is above $50 \%$ of $1 R M$ and adaptations occur predominantly locally in the trained skeletal muscles ${ }^{54,55}$. One of the main mechanisms behind RTinduced muscular adaptations of improving insulin sensitivity is thought to be an increased glucose transport into the myocytes by increased glucose transporter type four (GLUT 4) production, which is the primary transporter facilitating diffusion of circulating glucose into the skeletal muscle cells ${ }^{56}$, 57. 
Capillary growth likely occurs in parallel with enlargement of muscle fibers and, thus, capillary density is predominantly maintained in hypertrophied muscles with $\mathrm{RT}^{58}$. M itochondrial content is mainly maintained or reduced following RT ${ }^{59}$. Chronic RT may induce no change or improvements in blood pressure ${ }^{60-62}$ and blood lipid profile, of which reductions in LDL cholesterol appears to be a recurrent finding with $\mathrm{RT}^{63-65}$. In terms of cardiac morphological changes, resistance-trained athletes may have normal internal diameters but significantly thicker left ventricular wall, referred as to a concentric hypertrophy, although the research findings are not consistent ${ }^{66-69}$. Generally, long-term $\mathrm{RT}$ is beneficial for body composition by inducing increases in fat-free mass and decreases in fat mass, which may result in an increased resting metabolic rate ${ }^{70-72}$.

\section{Molecular adaptations to resistance training}

Skeletal muscle demonstrates a remarkable malleability to respond and adapt to contractile activity. The physiological stress by a resistance exercise bout is thought to disrupt cellular homeostasis. Cells react to stress by altering cellular functions to restore homeostasis during and after the exercise bout. Repeated disruptions of homeostasis, followed by sufficient recovery, generate gradually structural and functional adaptations in muscle tissue associated with long-term RT ("progressive overload principle") ${ }^{73,74}$.

From a molecular perspective, RT adaptations are based on the accumulation of specific proteins that alter cellular properties. Remodeling of skeletal muscle starts by loading-specific stimuli that affect the activation of a complex network of intracellular signaling pathways. These signals mediate alterations in enzyme activities, gene expression, and protein biosynthesis, which finally will modulate muscle proteome (Figure 4.1). Thus, the functional outcomes of RT, such as muscle mass gains and metabolic improvements, are coupled to the specificity of molecular responses ${ }^{2,75}$. Although acknowledging that the molecular network regulating skeletal muscle adaptations to RT is vast and affected by numerous factors, this chapter only briefly reviews a few mechanisms that have been suggested to be key players in adaptation to RT in humans.

\section{Stimuli for muscle adaptations to resistance training}

\section{Mechanical stress}

The mechanical tensile stress (stretch) is one important stressor associated with RT. All forms of muscular activity, whether eccentric or concentric, result in tension (force) through the active muscle(s). Tension associated with RT disturbs the integrity of skeletal muscle, causing mechanochemically transduced molecular and cellular responses (mechanotransduction), favoring anabolism in myofibers and satellite cells. Mechanical stress can induce intracellular responses also independently of growth factors ${ }^{76-79}$.

Mechanical stress induced by high force contractions during the resistance exercise is sensed in loaded muscles by various mechanisms. Mechanical stress induces the release of growth factors, such as IGF-I and hepatocyte growth factor (HGF), from the extracellular matrix. HGF can interact with satellite cells and activate signaling events leading to satellite cell proliferation ${ }^{80-82}$. M uscle contractions transiently disrupt the sarcolemma (the lipid bilayer that surrounds a muscle cell) integrity, which increases the concentration of membrane lipid phosphatidic acid (PA), leading to the activation of signaling pathways inducing hypertrophy ${ }^{83-85}$. M echanical stress generated in sarcomeres is transferred to the extracellular matrix via costameres, which is a protein complex that connects peripheral myofibrillis via the z-disks with the sarcolemma. The costamere comprises a dystrophin/glycoprotein complex and focal adhesion complex, which includes the transmembrane receptor integrin. Activation of integrin can induce hypertrophic signal transduction pathways 
through focal adhesion kinases (FAK) ${ }^{86-90}$. The acute increase in intracellular hydration (cell swelling) may occur during the resistance exercise due to lactate accumulation, contributing to the osmotic gradient in skeletal muscle. Increased intracellular pressure may threaten the structural integrity of the cell membrane and, thus, initiate anabolic intracellular signaling response via activation of integrin and focal adhesion proteins ${ }^{91-93}$. Titin is a flexible intrasarcomeric protein that contributes to force transmission and defines the passive stiffness of skeletal muscle. Titin is a likely candidate to sense alterations of mechanical load and interact with diverse cellular signaling pathways inducing hypertrophy ${ }^{94,95}$. Stretch activated channels (SACS) are calcium and sodium permeable channels which open due to mechanical stress to the sarcolemma. SACs may act as mechanosensor by allowing an influx of calcium ion $\left(\mathrm{Ca}^{2+}\right)$ into the myofiber that activates $\mathrm{Ca}^{2+}$ dependent hypertrophic intracellular signaling pathways ${ }^{96-98}$.

\section{Metabolic stress}

In addition to mechanical stress, also metabolic stress associated with RT can promote muscle adaptations ${ }^{99}$. A high rate of ATP turnover during muscle contractions and consequent accumulation of $A M P$, the release of $\mathrm{Ca}^{2+}$ from the sarcoplasmic reticulum, and local hypoxia in exercising muscles may stimulate energy-sensing signaling pathways regulating energy metabolism during the resistance exercise ${ }^{2,74,76}$. Generally, metabolic stress increases during resistance exercise in an intensity/volume-dependent manner. Presumably, high metabolic stress together with high mechanical strain could be achieved by a hypertrophy-oriented resistance exercise protocol of 6-12 repetitions per set with each set performed until failure, and with relatively short rest periods between the sets ${ }^{100,101}$.

Hypoxia. Local tissue hypoxia may occur during resistance exercise. Hypoxia is a major cellular stressor and oxygen sensing is well established in the regulation of adaptive processes in cells ${ }^{102}$. HIF-1 is considered as the master regulator of signal transduction pathways sensitive to the changes in intracellular partial pressure of oxygen (PiO2). Activation of HIF-1 induces transcription of target genes involved in promotion of glucose metabolism and glycolysis, erythropoiesis, and angiogenesis 2,74

REDOX state. Skeletal muscle significantly generates reactive oxygen species (ROS), reactive nitrogen species (RNS), and nitric oxide (NO) during contractile activity. The generation of ROS is dependent on cellular antioxidant capacity and ROS regulates its own defense by promoting cellular antioxidants to maintain redox balance at rest and during the exercise ${ }^{103,104}$. During resistance exercise, ROS production is likely increased, and it has been suggested to be an important signal in muscle remodeling to a more oxidative phenotype ${ }^{105,106}$. In the context of human muscle hypertrophic responses to RT, NO may mediate the activation of satellite cells and ROS, if not expressed excessively, mediate activation of several intracellular signaling pathways, such as IGF-I and M itogen-Activated Protein Kinase (MAPK) cascades, that could be required for muscle growth ${ }^{82}$, 107,108

Calsium flux. Calcium facilitates the cross-bridge interaction between myosin and actin filaments during myofibrillar contraction. During muscle contractions, amplitude and duration of calcium oscillations depends on the level of force output by the muscle. Alterations of intracellular $\mathrm{Ca}^{2+}$ concentrations in myofibers modulate signaling activity of calcineurin and calmodulin-dependent protein kinase (CaM KII). $\mathrm{Ca}^{2+}$ signaling influences glucose transport, lipid uptake and oxidation, and regulates activity dependent muscle gene expressions that alter fiber type distribution by promoting slow fibre formation ${ }^{109,110 .}$. 


\section{Myofibrillar disruptions and inflammation processes}

Resistance exercise results at least to some extent in localized muscular damage, of the loaded muscles, depending on the volume and intensity of the exercise and the training history of the participant. Regular RT typically causes mild muscle damage (myofibrillar disruptions) and full recovery normally occurs within a few days ${ }^{111}$. M isalignment of the myofibrils and Z-line streaming are common characteristic following resistance exercise, especially if the training regimen involves predominantly eccentric muscle actions. It has been proposed that due to the specific neural activation strategy for eccentric contractions, as compared to concentric, fewer motor units are recruited for a given load. This would result in a greater requirement of force per active motor unit, predisposing recruited muscle fibres to disrupt especially following unaccustomed eccentric exercise 112-114. Eccentric training, however, has been shown to be especially effective in promoting muscle hypertrophy and strength gains ${ }^{115}$.

Resistance exercise-induced myofibrillar disruptions are likely caused by physical stress upon the muscle fibres (i.e. mechanical stress) and the result of metabolic deficiencies, possibly through the loss of $\mathrm{Ca}^{2+}$ homeostasis (i.e. metabolic stress) ${ }^{111}$. Exercise-induced myofibrillar disruptions may elicit a local acute inflammatory response to promote clearance of damaged tissue and muscle regeneration. Inflammatory responses result in movement of fluid, plasma proteins and leukocytes to the site of cellular disruption that is manifested as delayed onset of muscle soreness, muscle stiffness and swelling, and transient decrease of force-generating capacity in loaded muscles ${ }^{116-118}$.

The infiltration of immune cells to the damaged muscles may be observed within 2-3 days following injury. The inflammatory response promotes clearance of damaged tissue and the regeneration of the damaged muscle fibres. The acute inflammatory response after the exercise includes infiltration of neutrophils and local release of proinflammatory cytokines, such as II-1, II-6 and TNF-alpha, which mediate protein breakdown ${ }^{119}$. Released cytokines may also stimulate proliferation of satellite cells 120. Subsequent secondary inflammation includes a significant infiltration of monocytes (i.e.precursors to macrophages) within the damaged muscle fiber to induce further phagocytic activity. Eventually, muscle tissue remodeling occurs during the regenerative phase following the exercise ${ }^{111,121}$.

\section{Systemic and local mediators of muscle plasticity: Hormones, growth factors and myokines}

Systemic hormones such as testosterone, growth hormone (GH), insulin, insulin-like growth factor (IGF-1) and cortisol can affect muscle mass and growth throughout lifespan. Depending on acute program variables, resistance exercise can elicit transient post-exercise increase in circulating hormone concentrations ${ }^{122,}{ }^{123}$. Endocrine responses during the exercise may be primarily due to regulation of whole body energy metabolism providing glucose and free fatty acids for energy in working muscles ${ }^{124,125}$. Hormones can induce their cellular effects through receptor interactions and systemic elevations of circulating hormones presumably increase the likelihood of interactions with receptors located within the muscle tissue and, thus, potentially effects on the responses of RT ${ }^{123}$. However, normal physiological fluctuations in hormones appear to play a preserving, rather than stimulatory, role in the regulation of muscle size ${ }^{126}$. In many studies, resting hormonal concentrations have not shown a significant change during RT despite increases in muscle strength and hypertrophy ${ }^{122,}{ }^{123}$. However, changes in testosterone and cortisol concentrations may reflect in some cases changes in training load and, thus, overall stress and recovery status in athletes ${ }^{127}$.

The anabolic effects of IGF-I in skeletal muscle have been clearly demonstrated but systemic IGF-I has only a limited influence on the hypertrophic response. However, local (autocrine/ paracrine) 
expressions of growth factors, such as IGF-I, within the loaded muscles in response to resistance exercise play probably an important role in skeletal muscle hypertrophy. IGF-I induces proliferation of satellite cells and enhance contractile protein accumulation in myofibers by activating IGF-I receptors in the cell membrane ${ }^{24}$. In contrast to IGF-I, myostatin is a major negative regulator of skeletal muscle growth. Myostatin is classified as a "myokine", i.e. it is produced and secreted by contracting muscle fibers, and subsequently exert auto-, para- and/or endocrine effects. M yostatin inhibits satellite cell activation, repress expression of myogenic regulatory factors and promote proteolysis. Myostatin effects target cells through the Smad2/3 signaling cascade by binding to Activin type II receptors ${ }^{76}$. In addition to myostatin and IGF-I, many other extracellular signaling molecules may potentially modulate skeletal muscle phenotype during resistance training ${ }^{128-132}$.

\section{Amino acids}

Protein availability is a potent modulator of acute molecular responses to resistance exercise. Essential amino acids, especially the branched-chain amino acid leucine, can independently stimulate signaling pathways that subsequently increase protein synthesis rates. Thus, essential amino acids not only act as a substrate but also a signal to promote protein synthetic responses ${ }^{110 \text {, }}$ ${ }^{133}$. Dietary protein intake appears to stimulate protein synthesis in a dose-dependent and saturable manner. Ingestion of $20 \mathrm{~g}$ of an isolated high-quality protein source, or $30 \mathrm{~g}$ of protein as part of a mixed meal, has been recommended to achieve maximal protein synthetic response ${ }^{134,135}$.

\section{Insert Figure 4.1 here}

Figure 4.1. Schematic overview of physiological stimuli by resistance exercise leading to adaptive responses. Depending on program variables, resistance exercise results in a specific milieu of mechanical and metabolic stimuli within the contracting muscle as well as systemic and local release of signaling molecules that lead to the activation of networks of signaling pathways and altered activity of cellular enzymes. These resistance exercise stimuli, together with nutrient availability, induce protein synthesis and tissue regeneration following the exercise. By chronic resistance training, positive net protein synthesis leads to muscle hypertrophy.

\section{Regulation of protein synthesis and degradation}

A bout of resistance exercise results in an increased rate of protein synthesis during recovery and a proportionately smaller and briefer increase in the protein degradation rate ${ }^{136,137}$. An acute bout of resistance training increases skeletal muscle protein turnover for up to $48 \mathrm{~h}$ after completion of exercise ${ }^{138}$. Increases in protein synthesis are suggested to be a result of an increased efficiency of translation per molecule of RNA ${ }^{139}$. The positive net protein synthetic response following resistance exercise results in an accretion of muscle protein over time ${ }^{140,141}$. Protein synthesis must exceed protein breakdown for an extended period (i.e. few weeks) until RT-induced muscle size changes are detectable ${ }^{142}$. It seems that unaccustomed exercise bouts lead to exaggerated local and systemic stress responses (e.g. dysregulated redox balance) and, thus, induce increases in protein synthesis ${ }^{75}$. However, repeated bouts of exercise blunt protein synthetic response, resulting in an attenuated increase in protein synthesis in the trained state ${ }^{143,144}$.

mTOR signaling. The most well-described mechanism by which dietary protein and exercise modulates skeletal muscle protein synthesis and subsequently fiber hypertrophy, is the mechanistic target of rapamycin complex 1 (mTORC1) signaling pathway ${ }^{145,146}$. The activation of $\mathrm{mTORC} 1$ is mediated via insulin/IGF-1 receptor activation by hormones and growth factors and the activation of the downstream phosphatidyl inositol-3 kinase (PI3K) - Akt pathway ${ }^{147}$. mTORCl can be activated 
also independently of Akt via contractile activity (mechanotransduction) and essential amino acid provision ${ }^{148-150}$.

Activation of mTORC1 triggers downstream signaling through p70 ribosomal S6 kinase (p70 S6K1), that is a key regulator of protein synthesis through canonical pathways of protein translation and ribosome biogenesis ${ }^{151,152}$. p70 S6K1 exerts its effect through ribosomal protein S6 (rpS6), eukaryotic elongation factor 2 kinase (eEF2), and eukaryotic initiation factor 4E-binding protein (4EBP1), which collectively increases mRNA translational efficiency and ultimately protein synthesis for cellular hypertrophy ${ }^{153,154}$. Increases in resistance exercise volume has been shown to induce pronounced activation of mTOR signaling proteins ${ }^{155-158}$. (Figure 4.2)

AM PK Signaling. The high rate of ATP turnover during the resistance exercise leads to a cellular energy deficit and increases in the AM P/ATP ratio. AM P-activated protein kinase (AM PK) senses the increase in energy turnover when muscle tissue is activated and acts as a signal transducer for metabolic adaptations ${ }^{159,}{ }^{160}$. Acute exercise increases AM PK enzymatic activity in an intensitydependent manner, reflecting effects of exercise on ATP turnover. Furthermore, contractioninduced $\mathrm{Ca}^{2+}$ release and ROS production leads to the activation of AM PK. As expected, resistance exercise has been shown to acutely increase AM PK activity in skeletal muscle ${ }^{161-163}$.

Overall, AM PK activation acts to conserve ATP by inhibiting biosynthetic and anabolic pathways, while simultaneously stimulating catabolic pathways to restore cellular energy stores. In skeletal muscle during the exercise, AM PK activation modulates cellular metabolism acutely through phosphorylation of metabolic enzymes that suppresses glycogen and protein synthesis, but promotes lipid metabolism and glucose uptake ${ }^{159,160,164}$. Protein synthesis is an energy-consuming process and, in agreement with the role as an energy sensor, activation of AM PK can suppress protein synthesis by inhibiting directly $\mathrm{mTORC1}$ activity or indirectly through mTOR upstream kinase tuberin (TSC2) activation ${ }^{162,165,166}$. AM PK can also inhibit protein synthesis through activation of eukaryotic translation elongation factor 2 kinase (eEF2K), leading to inhibition of protein translation by eEF2 ${ }^{4,167}$. Like AM PK, also energy sensors REDD1 (regulated in DNA damage and development 1) that is activated by ATP depletion and hypoxia-can inhibit mTORC1 and subsequently protein synthesis ${ }^{4,168}$. Chronic AM PK activation alters metabolic gene expression and induces mitochondrial biogenesis, leading to promotion of an oxidative muscle phenotype. The long-term regulatory actions are mediated via direct phosphorylation of transcription factors and the transcriptional coactivator PGC-1 $\alpha^{169,170 .}$

Protein degradation by the ubiquitin-proteasome system is regulated via muscle-specific E3 ubiquitin ligases, muscle atrophy $F$ box (atrogin-1/M AFbx) and muscle RING finger 1 (M URF1). They are involved in ubiquitination of specific proteins that are transferred to the $26 \mathrm{~S}$ proteasome for subsequent degradation ${ }^{171}$. For example, M uRF1-dependent ubiquitination regulates the degradation of contractile proteins, such as myosin heavy chains ${ }^{172}$. Transcriptional upregulation of atrogin-1/M AFbx and M uRF1 are increased by activation of the forkhead box 0 (FOXO) family of transcription factors ${ }^{173}$. Anabolic and energy sensitive processes regulate the ubiquitin-proteasome pathway activity. Akt, an upstream mediator of mTORC1 activity, inactivate FOXOs and, thus, inhibits proteolysis. Contrarily, AM PK activation promotes FOXOs activity ${ }^{110,174}$. Also, inflammatory response via the NF-kB pathway and myostatin promote proteolysis through ubiquitin proteasome system ${ }^{175-}$ 178 .

Autophagy refers to a process of non-selective degradation of cytosolic components by the lysosome. Autophagy is beneficial to maintain cellular homeostasis at rest as well as during the exercise and post-exercise recovery ${ }^{107,}{ }^{179}$. Resistance exercise may induce certain damage to loaded 
myofibers and autophagy enables removal of damaged organelles and proteins through the lysosomes. It appears that adaptation to exercise training is reliant on proper activation of autophagy, and acute physical exercise has been shown to be a potent inducer of autophagy in skeletal muscle ${ }^{180-183}$. Activity of autophagy is regulated through unc-51-like kinase 1 (ULK1). Activated $\mathrm{mTORC1}$ can inhibit autophagy while AM PK stimulates autophagy by regulation of ULK1 activity ${ }^{162,179,184,185}$. Besides the autophagy-lysosomal system, non-lysosomal proteases like the calcium-dependent calpain family and caspase class of proteins are involved in proteolysis ${ }^{105,186,187 .}$ For example, the sarcomeric damage caused by exercise initiates a calpain-mediated degradation of disrupted sarcomeric filaments, such as titin ${ }^{94}$.

\section{Insert Figure 4.2 here}

Figure 4.2. Simplified overview of mTOR and AM PK signaling pathways regulating skeletal muscle size and function by resistance exercise. Putative resistance exercise-induced stimuli (amino acids and contractile activity induced mechanic and metabolic stress, and release of systemic and local signaling molecules), activate specific intracellular signaling networks (including, but not limited to mTOR and AM PK signaling) that mediate acute and chronic skeletal muscle responses to resistance exercise training. Stimulation of the signaling pathways depends on the resistance exercise program variables used ${ }^{155-158,188-190}$. 4E-BP1, eukaryotic initiation factor 4E-binding protein 1; Akt, protein kinase B; AM PK, AM P-activated protein kinase; AS160, Akt substrate of $160 \mathrm{kDa}$; CaM K, calmodulindependent protein kinase; elF2B, eukaryotic initiation factor 2B; FAK, focal adhesion kinase; FoxO, forkhead box protein; GSK3, glycogen synthase kinase 3; mTORC1, mammalian/mechanistic target of rapamycin complex 1; p38 M APK, p38 mitogen-activated protein kinase; p70S6K, ribosomal S6 kinase $1 ;$ PA, phosphatidic acid; PGC-1 $\alpha$, peroxisome-proliferator-activated receptor gamma, coactivator 1 ; Rag, Ras-related small GTPase; RONS, reactive oxygen and nitrogen species; ULK1, Unc-51-like kinase 1. Arrows denote activation, oval arrows denote inhibition.

\section{Summary}

The aim of RT is to provide an overload stimulus across the muscle to generate specific molecular responses, promoting adaptive changes in skeletal muscle mass and metabolic function. The conversion of intra- and extracellular signals generated during muscle contractions to subsequent physiological adaptations involves a cascade of stimuli that affect specific signaling pathways regulating exercise-induced satellite cell activation, gene expression and/or protein turnover rate by proteosynthesis and proteolysis $24,110,126$.

RT-induced skeletal muscle hypertrophy appears to be significantly controlled by the activity of the translational machinery, where $\mathrm{mTORC1}$ acts as the master regulator. Several signaling pathways have an integrated effect on mTORC1 activity, of which autocrine/paracrine growth factors, mechanical and metabolic stress and amino acid availability appears to be the most prominent 2,74, ${ }^{76}$. However, RT-induced skeletal muscle adaptation is a complex process involving various cellular responses and many signal transduction pathways. Cellular signaling pathways comprise complex networks that are operative in constantly altering cellular milieu, making it difficult to connect specific signaling responses and changes in gene and protein expression to certain metabolic responses after a resistance exercise bout, let alone to long-term adaptations to $\mathrm{RT}^{191,192}$. In addition to the transcriptional and translational signaling networks involved with skeletal muscle plasticity, epigenetic modifications of DNA that may affect exercise-induced gene expression, or post-transcriptional silencing of genes by miRNAs, comprise additional levels of control on adaptations to $\mathrm{RT}^{193-197}$. 
To entirely understand the adaptive changes that myofibers undergo in response to RT in humans, aspects of the neuromuscular system (e.g. neural drive to muscles), musculoskeletal system (e.g. force transmission from muscles to tendons and bones), and cardiovascular system (e.g. muscle capillary network) should be taken into consideration. Furthermore, RT-induced adaptations generally affect the entire body, thus, adaptations in musculature should be viewed in the context of the crosstalk between tissues and organs in a whole body ${ }^{198-201}$. 


\section{References}

1. Folland JP, Williams AG. The adaptations to strength training : morphological and neurological contributions to increased strength. Sports Med 2007; 37:145-168.

2. Egan B, Zierath JR. Exercise metabolism and the molecular regulation of skeletal muscle adaptation. Cell Metab 2013; 17:162-184.

3. Westcott WL. Resistance training is medicine: effects of strength training on health. Curr Sports Med Rep 2012; 11:209-216.

4. Fyfe JJ, Bishop DJ, Stepto NK. Interference between concurrent resistance and endurance exercise: molecular bases and the role of individual training variables. Sports Med 2014; 44:743-762.

5. American College of Sports Medicine position stand. Progression models in resistance training for healthy adults. Med Sci Sports Exerc 2009; 41:687-708.

6. M urach KA, Bagley JR. Skeletal M uscle Hypertrophy with Concurrent Exercise Training: Contrary Evidence for an Interference Effect. Sports M ed 2016; 46:1029-1039.

7. Wernbom M, Augustsson J, Thomeé R. The influence of frequency, intensity, volume and mode of strength training on whole muscle cross-sectional area in humans. Sports M ed 2007; 37:225-264.

8. Ahtiainen JP, Walker S, Peltonen H, Holviala J, Sillanpää E, Karavirta L, et al. Heterogeneity in resistance training-induced muscle strength and mass responses in men and women of different ages. Age (Dordr) 2016; 38:10.

9. Hubal MJ, Gordish-Dressman H, Thompson PD, Price TB, Hoffman EP, Angelopoulos TJ, et al. Variability in muscle size and strength gain after unilateral resistance training. M ed Sci Sports Exerc 2005; 37:964-972. 
10. Konopka AR, Harber M P. Skeletal muscle hypertrophy after aerobic exercise training. Exerc Sport Sci Rev 2014; 42:53-61.

11. Hackett DA, Johnson NA, Chow C. Training practices and ergogenic aids used by male bodybuilders. J Strength Cond Res 2013; 27:1609-1617.

12. Schoenfeld BJ. The mechanisms of muscle hypertrophy and their application to resistance training. J Strength Cond Res 2010; 24:2857-2872.

13. Lüthi JM, Howald H, Claassen H, Rösler K, Vock P, Hoppeler H. Structural changes in skeletal muscle tissue with heavy-resistance exercise. Int J Sports Med 1986; 7:123-127.

14. Alway SE, M acDougall JD, Sale DG, Sutton JR, McComas AJ. Functional and structural adaptations in skeletal muscle of trained athletes. J Appl Physiol 1988; 64:1114-1120.

15. MacDougall JD, Elder GC, Sale DG, M oroz JR, Sutton JR. Effects of strength training and immobilization on human muscle fibres. Eur J Appl Physiol Occup Physiol 1980; 43:25-34.

16. Schiaffino S, Sandri M, M urgia M . Activity-dependent signaling pathways controlling muscle diversity and plasticity. Physiology (Bethesda) 2007; 22:269-278.

17. Fry AC. The role of resistance exercise intensity on muscle fibre adaptations. Sports M ed 2004; 34:663-679.

18. Yan Z, Okutsu M, Akhtar YN, Lira VA. Regulation of exercise-induced fiber type transformation, mitochondrial biogenesis, and angiogenesis in skeletal muscle. J Appl Physiol 2011; 110:264-274.

19. Narici M, Franchi M, M aganaris $C$. M uscle structural assembly and functional consequences. J Exp Biol 2016; 219:276-284. 
20. Lieber RL, Ward SR. Skeletal muscle design to meet functional demands. Philos Trans R Soc Lond, B, Biol Sci 2011; 366:1466-1476.

21. Franchi MV, Reeves ND, Narici M V. Skeletal M uscle Remodeling in Response to Eccentric vs. Concentric Loading: Morphological, M olecular, and M etabolic Adaptations. Front Physiol 2017; 8:447.

22. Degens $\mathrm{H}$, Erskine RM, M orse $\mathrm{Cl}$. Disproportionate changes in skeletal muscle strength and size with resistance training and ageing. J Musculoskelet Neuronal Interact 2009; 9:123-129.

23. Erskine RM, Jones DA, M affulli N, Williams AG, Stewart CE, Degens H. What causes in vivo muscle specific tension to increase following resistance training? Exp Physiol 2011; 96:145-155.

24. Favier FB, Benoit H, Freyssenet D. Cellular and molecular events controlling skeletal muscle mass in response to altered use. Pflugers Arch 2008; 456:587-600.

25. Blaauw B, Reggiani C. The role of satellite cells in muscle hypertrophy. J M uscle Res Cell M otil 2014; 35:3-10.

26. Allen DL, Roy RR, Edgerton VR. Myonuclear domains in muscle adaptation and disease. Muscle Nerve 1999; 22:1350-1360.

27. Snijders T, Nederveen JP, M cKay BR, Joanisse S, Verdijk LB, van Loon, Luc J C, et al. Satellite cells in human skeletal muscle plasticity. Front Physiol 2015; 6:283.

28. Gundersen K. Muscle memory and a new cellular model for muscle atrophy and hypertrophy. J Exp Biol 2016; 219:235-242.

29. Magnusson SP, Hansen P, Kjaer M. Tendon properties in relation to muscular activity and physical training. Scand J Med Sci Sports 2003; 13:211-223. 
30. Magnusson SP, Langberg H, Kjaer M. The pathogenesis of tendinopathy: balancing the response to loading. Nat Rev Rheumatol 2010; 6:262-268.

31. Reeves ND, M aganaris CN, Narici M V. Effect of strength training on human patella tendon mechanical properties of older individuals. J Physiol (Lond ) 2003; 548:971-981.

32. Kongsgaard M, Reitelseder S, Pedersen TG, Holm L, Aagaard P, Kjaer M, et al. Region specific patellar tendon hypertrophy in humans following resistance training. Acta Physiol (Oxf) 2007; 191:111-121.

33. Magnusson SP, Narici MV, Maganaris CN, Kjaer M. Human tendon behaviour and adaptation, in vivo. J Physiol (Lond ) 2008; 586:71-81.

34. Wiesinger H, Kösters A, Müller E, Seynnes OR. Effects of Increased Loading on In Vivo Tendon Properties: A Systematic Review. M ed Sci Sports Exerc 2015; 47:1885-1895.

35. Kongsgaard M, Kovanen V, Aagaard P, Doessing S, Hansen P, Laursen AH, et al. Corticosteroid injections, eccentric decline squat training and heavy slow resistance training in patellar tendinopathy. Scand J M ed Sci Sports 2009; 19:790-802.

36. Kubo K, Kanehisa H, Fukunaga T. Effects of resistance and stretching training programmes on the viscoelastic properties of human tendon structures in vivo. J Physiol (Lond ) 2002; 538:219-226.

37. Kubo K, Morimoto M, Komuro T, Yata H, Tsunoda N, Kanehisa H, et al. Effects of plyometric and weight training on muscle-tendon complex and jump performance. M ed Sci Sports Exerc 2007; 39:1801-1810.

38. Maïmoun L, Sultan C. Effects of physical activity on bone remodeling. M etab Clin Exp 2011; 60:373-388. 
39. Hawkins SA, Schroeder ET, Wiswell RA, Jaque SV, M arcell TJ, Costa K. Eccentric muscle action increases site-specific osteogenic response. Med Sci Sports Exerc 1999; 31:1287-1292.

40. Bolam KA, van Uffelen, J G Z, Taaffe DR. The effect of physical exercise on bone density in middle-aged and older men: a systematic review. Osteoporos Int 2013; 24:2749-2762.

41. Martyn-St James M, Carroll S. Effects of different impact exercise modalities on bone mineral density in premenopausal women: a meta-analysis. J Bone Miner M etab 2010; 28:251-267.

42. Knuiman P, Hopman MTE, M ensink M. Glycogen availability and skeletal muscle adaptations with endurance and resistance exercise. Nutr M etab (Lond) 2015; 12:59.

43. Essén-Gustavsson B, Tesch PA. Glycogen and triglyceride utilization in relation to muscle metabolic characteristics in men performing heavy-resistance exercise. Eur J Appl Physiol Occup Physiol 1990; 61:5-10.

44. Tesch PA, Colliander EB, Kaiser P. M uscle metabolism during intense, heavy-resistance exercise. Eur J Appl Physiol Occup Physiol 1986; 55:362-366.

45. Pascoe DD, Costill DL, Fink WJ, Robergs RA, Zachwieja JJ. Glycogen resynthesis in skeletal muscle following resistive exercise. Med Sci Sports Exerc 1993; 25:349-354.

46. Beelen M, Burke LM, Gibala MJ, van Loon L, J C. Nutritional strategies to promote postexercise recovery. Int J Sport Nutr Exerc M etab 2010; 20:515-532.

47. Doyle JA, Sherman WM, Strauss RL. Effects of eccentric and concentric exercise on muscle glycogen replenishment. J Appl Physiol 1993; 74:1848-1855.

48. Ivy JL. Regulation of muscle glycogen repletion, muscle protein synthesis and repair following exercise. J Sports Sci M ed 2004; 3:131-138. 
49. MacDougall JD, Ward GR, Sale DG, Sutton JR. Biochemical adaptation of human skeletal muscle to heavy resistance training and immobilization. J Appl Physiol Respir Environ Exerc Physiol 1977; 43:700-703.

50. Tesch PA, Alkner BA. Acute and Chronic M uscle Metabolic Adaptations to Strength Training. In: Komi PV, editor. Strength and Power in Sport. Blackwell Science Ltd: Oxford, UK265-280 p.

51. Pesta DH, Goncalves RLS, M adiraju AK, Strasser B, Sparks LM. Resistance training to improve type 2 diabetes: working toward a prescription for the future. Nutr M etab (Lond) 2017; 14:24.

52. LeBrasseur NK, Walsh K, Arany Z. M etabolic benefits of resistance training and fast glycolytic skeletal muscle. Am J Physiol Endocrinol M etab 2011; 300:3.

53. Sylow L, Kleinert M, Richter EA, Jensen TE. Exercise-stimulated glucose uptake - regulation and implications for glycaemic control. Nat Rev Endocrinol 2017; 13:133-148.

54. Colberg SR, Sigal RJ, Fernhall B, Regensteiner JG, Blissmer BJ, Rubin RR, et al. Exercise and type 2 diabetes: the American College of Sports Medicine and the American Diabetes Association: joint position statement. Diabetes Care 2010; 33:147.

55. Mann S, Beedie C, Balducci S, Zanuso S, Allgrove J, Bertiato F, et al. Changes in insulin sensitivity in response to different modalities of exercise: a review of the evidence. Diabetes M etab Res Rev $2014 ; 30: 257-268$.

56. Holten M K, Zacho M, Gaster M, Juel C, Wojtaszewski JFP, Dela F. Strength training increases insulin-mediated glucose uptake, GLUT4 content, and insulin signaling in skeletal muscle in patients with type 2 diabetes. Diabetes 2004; 53:294-305.

57. Strasser B, Pesta D. Resistance training for diabetes prevention and therapy: experimental findings and molecular mechanisms. Biomed Res Int 2013; 2013:805217. 
58. Hellsten Y, Nyberg M . Cardiovascular Adaptations to Exercise Training. Compr Physiol 2015; 6:132.

59. Groennebaek T, Vissing K. Impact of Resistance Training on Skeletal M uscle M itochondrial Biogenesis, Content, and Function. Front Physiol 2017; 8:713.

60. Mann S, Beedie C, Jimenez A. Differential effects of aerobic exercise, resistance training and combined exercise modalities on cholesterol and the lipid profile: review, synthesis and recommendations. Sports Med 2014; 44:211-221.

61. Gordon B, Chen S, Durstine JL. The effects of exercise training on the traditional lipid profile and beyond. Curr Sports Med Rep 2014; 13:253-259.

62. Tambalis K, Panagiotakos DB, Kavouras SA, Sidossis LS. Responses of blood lipids to aerobic, resistance, and combined aerobic with resistance exercise training: a systematic review of current evidence. Angiology 2009; 60:614-632.

63. Lemes ÍR, Ferreira PH, Linares SN, Machado AF, Pastre CM, Netto J. Resistance training reduces systolic blood pressure in metabolic syndrome: a systematic review and meta-analysis of randomised controlled trials. Br J Sports Med 2016.

64. Cornelissen VA, Fagard RH, Coeckelberghs E, Vanhees L. Impact of resistance training on blood pressure and other cardiovascular risk factors: a meta-analysis of randomized, controlled trials. Hypertension 2011; 58:950-958.

65. Strasser B, Siebert U, Schobersberger W. Resistance training in the treatment of the metabolic syndrome: a systematic review and meta-analysis of the effect of resistance training on metabolic clustering in patients with abnormal glucose metabolism. Sports M ed 2010; 40:397-415. 
66. M ihl C, Dassen WRM, Kuipers H. Cardiac remodelling: concentric versus eccentric hypertrophy in strength and endurance athletes. Neth Heart J 2008; 16:129-133.

67. Spence AL, Naylor LH, Carter HH, Buck CL, Dembo L, M urray CP, et al. A prospective randomised longitudinal M RI study of left ventricular adaptation to endurance and resistance exercise training in humans. J Physiol (Lond ) 2011; 589:5443-5452.

68. Santoro A, Alvino F, Antonelli G, Caputo M, Padeletti M , Lisi M, et al. Endurance and Strength Athlete's Heart: Analysis of M yocardial Deformation by Speckle Tracking Echocardiography. J Cardiovasc Ultrasound 2014; 22:196-204.

69. Utomi V, Oxborough D, Whyte GP, Somauroo J, Sharma S, Shave R, et al. Systematic review and meta-analysis of training mode, imaging modality and body size influences on the morphology and function of the male athlete's heart. Heart 2013; 99:1727-1733.

70. Fleck SJ , Kraemer WJ. 2014. Designing resistance training programs. Human Kinetics: Champaign, III. $109-115 p$.

71. St-Onge M, Gallagher D. Body composition changes with aging: the cause or the result of alterations in metabolic rate and macronutrient oxidation? Nutrition 2010; 26:152-155.

72. Sparti A, DeLany JP, de la Bretonne, J A, Sander GE, Bray GA. Relationship between resting metabolic rate and the composition of the fat-free mass. M etab Clin Exp 1997; 46:1225-1230.

73. Hawley JA. M olecular responses to strength and endurance training: are they incompatible? Appl Physiol Nutr M etab 2009; 34:355-361.

74. Hoppeler H. Molecular networks in skeletal muscle plasticity. J Exp Biol 2016; 219:205-213. 
75. Petriz BA, Gomes CPC, Almeida JA, de Oliveira GP, Ribeiro FM, Pereira RW, et al. The Effects of Acute and Chronic Exercise on Skeletal M uscle Proteome. J Cell Physiol 2017; 232:257-269.

76. Blaauw B, Schiaffino S, Reggiani C. Mechanisms modulating skeletal muscle phenotype. Compr Physiol 2013; 3:1645-1687.

77. Toigo M, Boutellier U. New fundamental resistance exercise determinants of molecular and cellular muscle adaptations. Eur J Appl Physiol 2006; 97:643-663.

78. Rindom E, Vissing K. M echanosensitive M olecular Networks Involved in Transducing Resistance Exercise-Signals into M uscle Protein Accretion. Front Physiol 2016; 7:547.

79. Philp A, Hamilton DL, Baar K. Signals mediating skeletal muscle remodeling by resistance exercise: PI3-kinase independent activation of mTORC1. J Appl Physiol 2011; 110:561-568.

80. Sheehan SM, Allen RE. Skeletal muscle satellite cell proliferation in response to members of the fibroblast growth factor family and hepatocyte growth factor. J Cell Physiol 1999; 181:499-506.

81. Tatsumi R, Anderson JE, Nevoret C], Halevy O, Allen RE. HGF/SF is present in normal adult skeletal muscle and is capable of activating satellite cells. Dev Biol 1998; 194:114-128.

82. Tatsumi R. M echano-biology of skeletal muscle hypertrophy and regeneration: possible mechanism of stretch-induced activation of resident myogenic stem cells. Anim Sci J 2010; 81:11-20.

83. Wang X, Devaiah SP, Zhang W, Welti R. Signaling functions of phosphatidic acid. Prog Lipid Res 2006; 45:250-278.

84. You J, Lincoln HC, Kim C, Frey JW, Goodman CA, Zhong X, et al. The role of diacylglycerol kinase $\zeta$ and phosphatidic acid in the mechanical activation of mammalian target of rapamycin (mTOR) signaling and skeletal muscle hypertrophy. J Biol Chem 2014; 289:1551-1563. 
85. Bond P. Phosphatidic acid: biosynthesis, pharmacokinetics, mechanisms of action and effect on strength and body composition in resistance-trained individuals. Nutr M etab (Lond) 2017; 14:12.

86. Malik RK, Parsons JT. Integrin-dependent activation of the p70 ribosomal S6 kinase signaling pathway. J Biol Chem 1996; 271:29785-29791.

87. Flück M, Carson JA, Gordon SE, Ziemiecki A, Booth FW. Focal adhesion proteins FAK and paxillin increase in hypertrophied skeletal muscle. Am J Physiol 1999; 277:152.

88. Crossland H, Kazi AA, Lang CH, Timmons JA, Pierre P, Wilkinson DJ, et al. Focal adhesion kinase is required for IGF-I-mediated growth of skeletal muscle cells via a TSC2/mTOR/S6K1-associated pathway. Am J Physiol Endocrinol M etab 2013; 305:183.

89. Kosek DJ, Bamman M M. M odulation of the dystrophin-associated protein complex in response to resistance training in young and older men. J Appl Physiol 2008; 104:1476-1484.

90. Klossner S, Durieux A, Freyssenet D, Flueck M. M echano-transduction to muscle protein synthesis is modulated by FAK. Eur J Appl Physiol 2009; 106:389-398.

91. Sjøgaard G. Water and electrolyte fluxes during exercise and their relation to muscle fatigue. Acta Physiol Scand Suppl 1986; 556:129-136.

92. Schliess F, Richter L, vom Dahl S, Häussinger D. Cell hydration and mTOR-dependent signalling. Acta Physiol (Oxf) 2006; 187:223-229.

93. Lambert IH, Hoffmann EK, Pedersen SF. Cell volume regulation: physiology and pathophysiology. Acta Physiol (Oxf) 2008; 194:255-282.

94. Krüger M , Kötter S. Titin, a Central M ediator for Hypertrophic Signaling, Exercise-Induced Mechanosignaling and Skeletal Muscle Remodeling. Front Physiol 2016; 7:76. 
95. Lange S, Xiang F, Yakovenko A, Vihola A, Hackman P, Rostkova E, et al. The kinase domain of titin controls muscle gene expression and protein turnover. Science 2005; 308:1599-1603.

96. Al-Shanti N, Stewart CE. Ca2+/calmodulin-dependent transcriptional pathways: potential mediators of skeletal muscle growth and development. Biol Rev Camb Philos Soc 2009; 84:637-652.

97. Spangenburg EE, M cBride TA. Inhibition of stretch-activated channels during eccentric muscle contraction attenuates p70S6K activation. J Appl Physiol 2006; 100:129-135.

98. Butterfield TA, Best TM. Stretch-activated ion channel blockade attenuates adaptations to eccentric exercise. Med Sci Sports Exerc 2009; 41:351-356.

99. Feriche B, García-Ramos A, M orales-Artacho AJ, Padial P. Resistance Training Using Different Hypoxic Training Strategies: a Basis for Hypertrophy and M uscle Power Development. Sports M ed Open 2017; 3:12.

100. Pearson SJ, Hussain SR. A review on the mechanisms of blood-flow restriction resistance training-induced muscle hypertrophy. Sports M ed 2015; 45:187-200.

101. Schoenfeld BJ. The mechanisms of muscle hypertrophy and their application to resistance training. J Strength Cond Res 2010; 24:2857-2872.

102. Scott BR, Slattery KM, Sculley DV, Dascombe BJ. Hypoxia and resistance exercise: a comparison of localized and systemic methods. Sports M ed 2014; 44:1037-1054.

103. Jackson M J, Pye D, Palomero J. The production of reactive oxygen and nitrogen species by skeletal muscle. J Appl Physiol 2007; 102:1664-1670.

104. Powers SK, Talbert EE, Adhihetty PJ. Reactive oxygen and nitrogen species as intracellular signals in skeletal muscle. J Physiol (Lond ) 2011; 589:2129-2138. 
105. Powers SK, Duarte J, Kavazis AN, Talbert EE. Reactive oxygen species are signalling molecules for skeletal muscle adaptation. Exp Physiol 2010; 95:1-9.

106. Jackson MJ, Vasilaki A, M cArdle A. Cellular mechanisms underlying oxidative stress in human exercise. Free Radic Biol M ed 2016; 98:13-17.

107. Ferraro E, Giammarioli AM, Chiandotto S, Spoletini I, Rosano G. Exercise-Induced Skeletal Muscle Remodeling and M etabolic Adaptation: Redox Signaling and Role of Autophagy. Antioxidants \& Redox Signaling 2014; 21:154-176.

108. Steinbacher P, Eckl P. Impact of oxidative stress on exercising skeletal muscle. Biomolecules $2015 ; 5: 356-377$

109. Wright DC, Geiger PC, Han D, Jones TE, Holloszy JO. Calcium induces increases in peroxisome proliferator-activated receptor gamma coactivator-1alpha and mitochondrial biogenesis by a pathway leading to p38 mitogen-activated protein kinase activation. J Biol Chem 2007; 282:1879318799.

110. M argolis LM , Rivas DA. Implications of exercise training and distribution of protein intake on molecular processes regulating skeletal muscle plasticity. Calcif Tissue Int 2015; 96:211-221.

111. Tee JC, Bosch AN, Lambert MI. M etabolic consequences of exercise-induced muscle damage. Sports Med 2007; 37:827-836.

112. Douglas J, Pearson S, Ross A, M cGuigan M. Eccentric Exercise: Physiological Characteristics and Acute Responses. Sports Med 2017; 47:663-675.

113. Proske U, M organ DL. Muscle damage from eccentric exercise: mechanism, mechanical signs, adaptation and clinical applications. J Physiol (Lond ) 2001; 537:333-345. 
114. Duchateau J, Enoka RM . Neural control of lengthening contractions. J Exp Biol 2016; 219:197204.

115. Roig M , O'Brien K, Kirk G, M urray R, M cKinnon P, Shadgan B, et al. The effects of eccentric versus concentric resistance training on muscle strength and mass in healthy adults: a systematic review with meta-analysis. $\mathrm{Br}$ J Sports Med 2009; 43:556-568.

116. Paulsen G, M ikkelsen UR, Raastad T, Peake JM . Leucocytes, cytokines and satellite cells: what role do they play in muscle damage and regeneration following eccentric exercise? Exerc Immunol Rev 2012; 18:42-97.

117. Hyldahl RD, Hubal MJ. Lengthening our perspective: morphological, cellular, and molecular responses to eccentric exercise. M uscle Nerve 2014; 49:155-170.

118. Howatson G, van Someren KA. The prevention and treatment of exercise-induced muscle damage. Sports M ed 2008; 38:483-503.

119. Kerksick CM, Willoughby D, Kouretas D, Tsatsakis A. Intramuscular responses with muscle damaging exercise and the interplay between multiple intracellular networks: a human perspective. Food Chem Toxicol 2013; 61:136-143.

120. Peake JM, Neubauer O, Della Gatta PA, Nosaka K. M uscle damage and inflammation during recovery from exercise. J Appl Physiol 2017; 122:559-570.

121. Tidball JG. Regulation of muscle growth and regeneration by the immune system. Nat Rev Immunol 2017; 17:165-178.

122. Gonzalez AM, Hoffman JR, Stout JR, Fukuda DH, Willoughby DS. Intramuscular Anabolic Signaling and Endocrine Response Following Resistance Exercise: Implications for M uscle Hypertrophy. Sports Med 2016; 46:671-685. 
123. Kraemer WJ, Ratamess NA. Hormonal responses and adaptations to resistance exercise and training. Sports Med 2005; 35:339-361.

124. Hansen D, M eeusen R, Mullens A, Dendale P. Effect of acute endurance and resistance exercise on endocrine hormones directly related to lipolysis and skeletal muscle protein synthesis in adult individuals with obesity. Sports M ed 2012; 42:415-431.

125. M cM urray RG, Hackney AC. Interactions of metabolic hormones, adipose tissue and exercise. Sports M ed 2005; 35:393-412.

126. M arcotte GR, West DWD, Baar K. The molecular basis for load-induced skeletal muscle hypertrophy. Calcif Tissue Int 2015; 96:196-210.

127. Crewther BT, Cook C, Cardinale M, Weatherby RP, Lowe T. Two emerging concepts for elite athletes: the short-term effects of testosterone and cortisol on the neuromuscular system and the dose-response training role of these endogenous hormones. Sports M ed 2011; 41:103-123.

128. Catoire M , Kersten S. The search for exercise factors in humans. Faseb J 2015; 29:1615-1628.

129. Lightfoot AP, Cooper RG. The role of myokines in muscle health and disease. Curr Opin Rheumatol 2016; 28:661-666.

130. Huh JY. The role of exercise-induced myokines in regulating metabolism. Arch Pharm Res 2018; 41:14-29.

131. Oh K, Lee DS, Kim WK, Han BS, Lee SC, Bae K. Metabolic Adaptation in Obesity and Type II Diabetes: M yokines, Adipokines and Hepatokines. Int J Mol Sci 2016; 18. 
132. Zanou N, Gailly P. Skeletal muscle hypertrophy and regeneration: interplay between the myogenic regulatory factors (M RFs) and insulin-like growth factors (IGFs) pathways. Cell M ol Life Sci 2013; 70:4117-4130.

133. M oro T, Ebert SM , Adams CM , Rasmussen BB. Amino Acid Sensing in Skeletal M uscle. Trends Endocrinol Metab 2016; 27:796-806.

134. Jäger R, Kerksick CM , Campbell BI, Cribb PJ, Wells SD, Skwiat TM , et al. International Society of Sports Nutrition Position Stand: protein and exercise. J Int Soc Sports Nutr 2017; 14:20.

135. M orton RW, M cGlory C, Phillips SM. Nutritional interventions to augment resistance traininginduced skeletal muscle hypertrophy. Front Physiol 2015; 6:245.

136. Biolo G, Maggi SP, Williams BD, Tipton KD, Wolfe RR. Increased rates of muscle protein turnover and amino acid transport after resistance exercise in humans. Am J Physiol 1995; 268:514.

137. Kumar V, Atherton P, Smith K, Rennie MJ. Human muscle protein synthesis and breakdown during and after exercise. J Appl Physiol 2009; 106:2026-2039.

138. Phillips SM, Tipton KD, Aarsland A, W olf SE, Wolfe RR. M ixed muscle protein synthesis and breakdown after resistance exercise in humans. Am J Physiol 1997; 273:99.

139. Chesley A, MacDougall JD, Tarnopolsky MA, Atkinson SA, Smith K. Changes in human muscle protein synthesis after resistance exercise. J Appl Physiol 1992; 73:1383-1388.

140. Atherton PJ, Smith K. Muscle protein synthesis in response to nutrition and exercise. J Physiol (Lond ) 2012; 590:1049-1057.

141. Rennie MJ, Wackerhage H, Spangenburg EE, Booth FW. Control of the size of the human muscle mass. Annu Rev Physiol 2004; 66:799-828. 
142. Seynnes OR, de Boer M , Narici MV. Early skeletal muscle hypertrophy and architectural changes in response to high-intensity resistance training. J Appl Physiol 2007; 102:368-373.

143. Kim PL, Staron RS, Phillips SM . Fasted-state skeletal muscle protein synthesis after resistance exercise is altered with training. J Physiol (Lond ) 2005; 568:283-290.

144. Tang JE, Perco JG, M oore DR, Wilkinson SB, Phillips SM. Resistance training alters the response of fed state mixed muscle protein synthesis in young men. Am J Physiol Regul Integr Comp Physiol $2008 ; 294: 172$.

145. Bodine SC, Stitt TN, Gonzalez M, Kline WO, Stover GL, Bauerlein R, et al. Akt/mTOR pathway is a crucial regulator of skeletal muscle hypertrophy and can prevent muscle atrophy in vivo. Nat Cell Biol 2001; 3:1014-1019.

146. Drummond MJ, Fry CS, Glynn EL, Dreyer HC, Dhanani S, Timmerman KL, et al. Rapamycin administration in humans blocks the contraction-induced increase in skeletal muscle protein synthesis. J Physiol (Lond ) 2009; 587:1535-1546.

147. Deldicque $L$, Theisen D, Francaux M . Regulation of mTOR by amino acids and resistance exercise in skeletal muscle. Eur J Appl Physiol 2005; 94:1-10.

148. Goberdhan DCl, Wilson C, Harris AL. Amino Acid Sensing by mTORC1: Intracellular Transporters Mark the Spot. Cell M etab 2016; 23:580-589.

149. Bond P. Regulation of mTORC1 by growth factors, energy status, amino acids and mechanical stimuli at a glance. J Int Soc Sports Nutr 2016; 13:8.

150. Jacobs BL, Goodman CA, Hornberger TA. The mechanical activation of mTOR signaling: an emerging role for late endosome/lysosomal targeting. J M uscle Res Cell M otil 2014; 35:11-21. 
151. Ma XM , Blenis J. M olecular mechanisms of mTOR-mediated translational control. Nat Rev M ol Cell Biol 2009; 10:307-318.

152. Proud CG. Signalling to translation: how signal transduction pathways control the protein synthetic machinery. Biochem J 2007; 403:217-234.

153. Goodman CA. The role of $\mathrm{mTORC1}$ in regulating protein synthesis and skeletal muscle mass in response to various mechanical stimuli. Rev Physiol Biochem Pharmacol 2014; 166:43-95.

154. Ben-Sahra I, M anning BD. mTORC1 signaling and the metabolic control of cell growth. Curr Opin Cell Biol 2017; 45:72-82.

155. Ahtiainen JP, Walker S, Silvennoinen M, Kyröläinen H, Nindl BC, Häkkinen K, et al. Exercise type and volume alter signaling pathways regulating skeletal muscle glucose uptake and protein synthesis. Eur J Appl Physiol 2015; 115:1835-1845.

156. Burd NA, Holwerda AM, Selby KC, West DWD, Staples AW, Cain NE, et al. Resistance exercise volume affects myofibrillar protein synthesis and anabolic signalling molecule phosphorylation in young men. J Physiol (Lond ) 2010; 588:3119-3130.

157. Hulmi JJ, Walker S, Ahtiainen JP, Nyman K, Kraemer WJ, Häkkinen K. M olecular signaling in muscle is affected by the specificity of resistance exercise protocol. Scand J Med Sci Sports 2012; 22:240-248.

158. Terzis G, Spengos K, M ascher H, Georgiadis G, Manta P, Blomstrand E. The degree of p70 S6k and $\mathbf{S 6}$ phosphorylation in human skeletal muscle in response to resistance exercise depends on the training volume. Eur J Appl Physiol 2010; 110:835-843.

159. Kjøbsted R, Hingst JR, Fentz J, Foretz M, Sanz M , Pehmøller C, et al. AM PK in skeletal muscle function and metabolism. Faseb J 2017. 
160. M ounier $R$, Théret $M$, Lantier $L$, Foretz $M$, Viollet $B$. Expanding roles for AM PK in skeletal muscle plasticity. Trends Endocrinol M etab 2015; 26:275-286.

161. Vissing K, M cGee SL, Farup J, Kjølhede T, Vendelbo MH, Jessen N. Differentiated mTOR but not AM PK signaling after strength vs endurance exercise in training-accustomed individuals. Scand J Med Sci Sports 2013; 23:355-366.

162. J essen N, Sundelin EIO, Møller AB. AMP kinase in exercise adaptation of skeletal muscle. Drug Discov Today 2014; 19:999-1002.

163. M orales-Alamo D, Calbet JAL. AM PK signaling in skeletal muscle during exercise: Role of reactive oxygen and nitrogen species. Free Radic Biol Med 2016; 98:68-77.

164. Baar K. Using molecular biology to maximize concurrent training. Sports M ed 2014; 44 Suppl 2:117.

165. Bolster DR, Crozier SJ, Kimball SR, Jefferson LS. AM P-activated protein kinase suppresses protein synthesis in rat skeletal muscle through down-regulated mammalian target of rapamycin (mTOR) signaling. J Biol Chem 2002; 277:23977-23980.

166. Dreyer HC, Fujita S, Cadenas JG, Chinkes DL, Volpi E, Rasmussen BB. Resistance exercise increases AM PK activity and reduces 4E-BP1 phosphorylation and protein synthesis in human skeletal muscle. J Physiol (Lond ) 2006; 576:613-624.

167. Horman S, Browne G, Krause U, Patel J, Vertommen D, Bertrand L, et al. Activation of AMPactivated protein kinase leads to the phosphorylation of elongation factor 2 and an inhibition of protein synthesis. Curr Biol 2002; 12:1419-1423. 
168. Gordon BS, Steiner JL, Williamson DL, Lang CH, Kimball SR. Emerging role for regulated in development and DNA damage 1 (REDD1) in the regulation of skeletal muscle metabolism. Am J Physiol Endocrinol M etab 2016; 311:157.

169. Lira VA, Benton CR, Yan Z, Bonen A. PGC-1alpha regulation by exercise training and its influences on muscle function and insulin sensitivity. Am J Physiol Endocrinol Metab 2010; 299:145.

170. Thirupathi A, de Souza CT. M ulti-regulatory network of ROS: the interconnection of ROS, PGC-1 alpha, and AM PK-SIRT1 during exercise. J Physiol Biochem 2017; 73:487-494.

171. Sandri M. Signaling in muscle atrophy and hypertrophy. Physiology (Bethesda) 2008; 23:160170.

172. Clarke BA, Drujan D, Willis M S, M urphy LO, Corpina RA, Burova E, et al. The E3 Ligase MuRF1 degrades myosin heavy chain protein in dexamethasone-treated skeletal muscle. Cell M etab 2007; 6:376-385.

173. Bodine SC, Baehr LM . Skeletal muscle atrophy and the E3 ubiquitin ligases M URF1 and MAFbx/atrogin-1. Am J Physiol Endocrinol Metab 2014; 307:469.

174. Léger B, Cartoni R, Praz M, Lamon S, Dériaz O, Crettenand A, et al. Akt signalling through GSK3beta, mTOR and Foxo1 is involved in human skeletal muscle hypertrophy and atrophy. J Physiol (Lond ) 2006; 576:923-933.

175. M urton AJ, Constantin D, Greenhaff PL. The involvement of the ubiquitin proteasome system in human skeletal muscle remodelling and atrophy. Biochim Biophys Acta 2008; 1782:730-743.

176. Bilodeau PA, Coyne ES, Wing SS. The ubiquitin proteasome system in atrophying skeletal muscle: roles and regulation. Am J Physiol , Cell Physiol 2016; 311:392. 
177. M cCarthy JJ, Esser KA. Anabolic and catabolic pathways regulating skeletal muscle mass. Curr Opin Clin Nutr Metab Care 2010; 13:230-235.

178. Turner M D, Nedjai B, Hurst T, Pennington DJ. Cytokines and chemokines: At the crossroads of cell signalling and inflammatory disease. Biochim Biophys Acta 2014; 1843:2563-2582.

179. Vainshtein A, Hood DA. The regulation of autophagy during exercise in skeletal muscle. J Appl Physiol 2016; 120:664-673.

180. M asiero E, Agatea L, Mammucari C, Blaauw B, Loro E, Komatsu M, et al. Autophagy is required to maintain muscle mass. Cell Metab 2009; 10:507-515.

181. Grumati P, Coletto L, Schiavinato A, Castagnaro S, Bertaggia E, Sandri M, et al. Physical exercise stimulates autophagy in normal skeletal muscles but is detrimental for collagen VI-deficient muscles. Autophagy 2011; 7:1415-1423.

182. Tam BT, Siu PM . Autophagic cellular responses to physical exercise in skeletal muscle. Sports Med 2014; 44:625-640.

183. M artin-Rincon M, M orales-Alamo D, Calbet JaL. Exercise-mediated modulation of autophagy in skeletal muscle. Scand J M ed Sci Sports 2017.

184. Alers S, Löffler AS, Wesselborg S, Stork B. Role of AM PK-mTOR-Ulk1/2 in the regulation of autophagy: cross talk, shortcuts, and feedbacks. M ol Cell Biol 2012; 32:2-11.

185. M ihaylova M M , Shaw RJ. The AM PK signalling pathway coordinates cell growth, autophagy and metabolism. Nat Cell Biol 2011; 13:1016-1023.

186. Baar K, Nader G, Bodine S. Resistance exercise, muscle loading/ unloading and the control of muscle mass. Essays Biochem 2006; 42:61-74. 
187. Pasiakos SM , Carbone JW. Assessment of skeletal muscle proteolysis and the regulatory response to nutrition and exercise. IUBM B Life 2014; 66:478-484.

188. M cKendry J, Pérez-López A, M cLeod M, Luo D, Dent JR, Smeuninx B, et al. Short inter-set rest blunts resistance exercise-induced increases in myofibrillar protein synthesis and intracellular signalling in young males. Exp Physiol 2016; 101:866-882.

189. M itchell C], Churchward-Venne TA, West DWD, Burd NA, Breen L, Baker SK, et al. Resistance exercise load does not determine training-mediated hypertrophic gains in young men. J Appl Physiol 2012; 113:71-77.

190. Popov DV, Lysenko EA, Bachinin AV, M iller TF, Kurochkina NS, Kravchenko IV, et al. Influence of resistance exercise intensity and metabolic stress on anabolic signaling and expression of myogenic genes in skeletal muscle. Muscle Nerve 2015; 51:434-442.

191. M cGlory C, Phillips SM . Exercise and the Regulation of Skeletal M uscle Hypertrophy. Prog M ol Biol Transl Sci 2015; 135:153-173.

192. Smiles WJ, Hawley JA, Camera DM . Effects of skeletal muscle energy availability on protein turnover responses to exercise. J Exp Biol 2016; 219:214-225.

193. Hitachi K, Tsuchida K. Role of microRNAs in skeletal muscle hypertrophy. Front Physiol 2013; $4: 408$

194. Kirby TJ, M cCarthy JJ. MicroRNAs in skeletal muscle biology and exercise adaptation. Free Radic Biol Med 2013; 64:95-105.

195. Rasmussen M, Zierath JR, Barrès R. Dynamic epigenetic responses to muscle contraction. Drug Discov Today 2014; 19:1010-1014. 
196. Sharples AP, Stewart CE, Seaborne RA. Does skeletal muscle have an 'epi'-memory? The role of epigenetics in nutritional programming, metabolic disease, aging and exercise. Aging Cell 2016; 15:603-616.

197. Silva GJJ, Bye A, El Azzouzi H, Wisløff U. MicroRNAs as Important Regulators of Exercise Adaptation. Prog Cardiovasc Dis 2017; 60:130-151.

198. Schnyder S, Handschin C. Skeletal muscle as an endocrine organ: PGC-1 $\alpha$, myokines and exercise. Bone 2015; 80:115-125.

199. Neufer PD, Bamman M M , M uoio DM , Bouchard C, Cooper DM , Goodpaster BH, et al. Understanding the Cellular and M olecular Mechanisms of Physical Activity-Induced Health Benefits. Cell M etab 2015; 22:4-11.

200. Hoffman NJ. Omics and Exercise: Global Approaches for Mapping Exercise Biological Networks. Cold Spring Harb Perspect M ed 2017; 7.

201. Giudice J, Taylor JM . M uscle as a paracrine and endocrine organ. Curr Opin Pharmacol 2017; 34:49-55. 